\title{
Direct costs of osteoporosis and hip fracture: An analysis for the Mexican Social Insurance Health Care System
}

\author{
Fernando Carlos, MHE, (') Patricia Clark, MD PhD, (1) Humberto Maciel, MD, Ms Adm, ${ }^{(2)}$ Juan A Tamayo, MD.(3)
}

\section{Carlos F, Clark P, Maciel H,Tamayo JA. Direct costs of osteoporosis and hip fracture: An analysis for the Mexican Social Insurance Health Care System. Salud Publica Mex 2009;5 I suppl I:SI08-SII3.}

\begin{abstract}
Objective. To compare costs of diagnosis and annual treatment of osteoporosis and hip fracture between the Instituto Nacional de Rehabilitación (INR) and the protocol used by the Seguro Popular de Salud (SPSS). Methods. Direct costs gathered in a prospective study with real cases at the INR are presented, and then this data is re-analyzed with the methodology and protocol for the SPSS to estimate the costs of those cases if treated with the SPSS protocol. Results. Important differences were found in the cost of hip fracture: the SPSS estimates ( $\$ 37363.73 \mathrm{MXN})$ almost double the INR cost ( $\$ 20286.86 \mathrm{MXN})$. This discrepancy was caused by the different types of surgeries the INR and SPSS protocols call for (the SPSS assumes that all hip fractures will necessitate a hip replacement) and the cost of subsequent hospitalization. A prospective study at the SPSS is needed to validate these results. Conclusions. Important differences were found between treatment of the same osteoporosis related problems at the INR and SPSS.We recommend revising the SPSS protocol to include less costly surgical treatments.
\end{abstract}

Key words: cost and cost analysis; osteoporosis; hip fractures; Mexico
Carlos F, Clark P, Maciel H,Tamayo JA.

Costos directos de la osteoporosis y fracturas de cadera: un análisis para el sistema de salud mexicano.

Salud Publica Mex 2009;5 I supl I:SI08-S I I3.

\section{Resumen}

Objetivo. Realizar una comparación de costos de diagnóstico y tratamiento anual de la osteoporosis y la fractura de cadera entre el Instituto Nacional de Rehabilitación (INR) y el protocolo utilizado por el Seguro Popular de Salud (SPSS). Material y métodos. Los costos directos obtenidos en un estudio prospectivo con casos reales en el INR fueron utilizados para realizar un escenario considerando la metodología y protocolo del SPSS para estimar los costos de este último. Resultados. Existen diferencias importantes en el costo de la fractura de cadera utilizando el escenario de SPSS; los costos estimados en SPSS fueron casi del doble respecto al INR (\$37 363.73 vs. $\$ 20286.86$ pesos). Las diferencias están dadas por el tipo y costo de la cirugía (el SPSS asume que todas las fracturas de cadera tengan un remplazo total de cadera) y el costo de la hospitalización. Se requiere un estudio prospectivo para validar estos resultados en el SPSS. Conclusiones. Se encontraron diferencias importantes entre el tratamiento de problemas relacionados con osteoporosis en el INR y el SPSS. Se recomienda revisar el protocolo del SPSS para incluir tratamientos quirúrgicos menos costosos.

Palabras clave: costos y análisis de costo; osteoporosis; fracturas de cadera; México

(I) Clinical Epidemiology Unit IMSS; Faculty of Medicine UNAM. Mexico.

(2) National Commission of Social Health Protection (Comisión Nacional de Protección Social en Salud). Mexico.

(3) Mexican Committee for the Prevention of Osteoporosis, COMOP. Mexico.

Received on: January 10, 2008 - Accepted on: September 30, 2008

Address reprint requests to: Patricia Clark MD PhD. Clinical Epidemiology Unit IMSS.

Blvd.Virreyes 1010, Lomas de Chapultepec. I 1000 Mexico City.

E-mail: patriciaclark@prodigy.net.mx 
$\mathrm{O}$ steoporosis (OP) has become a major health burden due to the cost of its most common complication, fragility fractures. ${ }^{1,2}$ In Mexico, 169 women and 98 men per 100000 person years were reported to have a hip fracture in the year 2000; 1 out of 12 women and 1 out of 20 men are predicted to sustain a hip fracture after 50 years of age, making hip fractures common in the Mexican population. ${ }^{3}$ The costs of the acute treatment of hip fractures in Mexico are high (over $\$ 97$ million US dollars in 2006) and are expected to grow as life expectancy and the number of elderly in the Mexican population increase. ${ }^{4}$ In 2003, the Mexican Congress approved a new social security system dedicated to paying for treatment at accredited medical Institutions that is not covered by the traditional Social Security Institutions IMSS and ISSSTE (which cover approximately 49 million of the 110 million population). 5 ,6 As of January 2007, this new Seguro Popular (SPSS) has enrolled 20 million Mexicans of all ages, particularly those living in the lowest three socioeconomic deciles, who frequently live in rural areas. With these figures, we estimate that at least 1000 hip fractures received surgical management paid for by SPSS in 2006.

We recently published ${ }^{4}$ an analysis of the direct costs of OP and hip fracture in the Mexican Health System, which did not include information on the cost paid by the new SPSS to their health providers. This study compares our data on the costs of OP and hip fracture for other government insurance programs and the cost authorized by SPSS for surgical management of hip fracture and for diagnosis and annual treatment of osteoporosis. ${ }^{7}$ This type of economic analysis is an important component of health research that helps policy makers to better allocate resources. In this case, comparing the costs of two treatment protocols within the same health system sheds light on the advantageousness of each program.

Our results can also be used to create practical clinical intervention guidelines for allocating SPSS resources most effectively. Early identification of patients at risk for fracture, as well as follow up and treatment of the population that has sustained a fracture with effective anti fracture measurements will yield better outcomes.

\section{Material and Methods}

For the present analysis we compared estimated costs for OP and hip fracture treatment at the SPSS with previously estimated costs for this treatment at the Instituto Nacional de Rehabilitación (INR), a health institution run by the Secretary of Health in Mexico City. These INR costs were estimated in a previous study in which 81 patients with OP (as defined by the WHO classification criteria) and one year of treatment with no fractures, and 61 patients with hip fractures received treatment at the INR. All patients were aged 50 or older. Resource use for OP diagnosis was obtained by consulting the protocol presented at the INR institutional web site. ${ }^{8}$ Resource use during a complete year of treatment after OP diagnosis and for the surgical management of a hip fracture was gathered from two different and complementary sources: a questionnaire specifically designed for this study that all the patients answered and a clinical chart review.

The costs of drugs were calculated on the basis of the wholesale prices listed in the 2007 pharmaceutical company bids made to governmental healthcare institutions. Unit costs of services were obtained from authorized cost recovery fees for patients at socioeconomic level 6 receiving medical attention at the INR during 2007. ${ }^{9}$

The protocol for this study was approved by the Institutional Research and Ethics Review Board at the Hospital de Especialidades CMN IMSS and written consent was obtained from all participants. ${ }^{4}$

\section{Estimates of costs}

The relevant units of every resource use per episode (OP or hip fracture) were multiplied by the unit cost to estimate the total cost per patient, according to the following formula:

Total cost per patient $=\sum_{i=1}^{n} Q_{i x}{ }^{*} P_{i}$

Where: $Q_{i x}=$ Number of units of resource " $i$ " used by patient " $x$ ", and $\mathrm{P}_{\mathrm{i}}=$ Unit cost of resource " $\mathrm{i}$ "

We added all these costs to calculate the total estimated costs of diagnosis and one-year treatment for OP, and the acute treatment for hip fracture. Total cost per patient was calculated as the total cost divided by the total number of patients with either OP or hip fracture. The analysis was performed under the public provider of services, assuming that the cost recovery fees paid by patients at socioeconomic level 6 reflect the true costs paid by the INR. A mixture of micro-costing and activitybased costing techniques for governmental institutions was used and a detailed explanation of the methods used are provided elsewhere. ${ }^{4}$ In a second step, the average resource use derived from the previous study was entered into a model of the costs for the SPSS.

The methods used to estimate the costs for the SPSS are as follows. At its inception, the SPSS calculated the 
per capita annual cost of treatment, in order to be able to pay for 249 medical interventions including prevention, diagnosis and treatment from authorized medical providers. $^{7}$

In order to calculate the annual per capita cost of each approved intervention, a group of experts analyzed the incidence and prevalence of each intervention and defined their cost. ${ }^{7}$ Clinical intervention guidelines that account for the various phases of the medical decision making process was used to create this estimate., 70 Final estimates include the human resources, materials, diagnostic tests, and drugs needed, as well as other factors like outpatient consultation, days of hospital stay, intensive care unit cost per day, operating room cost per hour, and unit cost of drugs and tests (clinical chemistry, $\mathrm{x}$-rays, bone density test, etc.)

With these basic production functions defined, the individual intervention cost was set using data matrices in a calculation sheet. To facilitate payment for the services provided, the basic unit cost was divided into its fixed and variable components.

Fixed costs include the infrastructure that belongs to the different medical institutions (provider) independently of treatment demand, including: the facility (hospital building), capital cost (instrumental, equipment and furniture costs), basic services (electricity, water supply, maintenance, taxes) and to the costs of human resources. These capital costs are summarized as basic measurement unit for each approved intervention, which are figured on an annual basis and are specific to the type of medical facility. A costing technique was used to establish the equivalent cost for each effective year of each particular capital good. ${ }^{7,11}$ Variable costs were defined using the official published catalogs for clinical chemistry laboratory, cabinet tests, drugs and materials and are based upon 2007 data.

\section{Results}

Cost estimations for diagnosis and annual treatment of $\mathrm{OP}$ and surgical management of hip fracture based on each protocol are provided below. Table I shows the resource utilization at the INR for these different diagnoses, and an average of the costs incurred for one year of treatment in the sample of patients studied at this institution. The standard protocol for diagnosis of OP patients at the INR includes two out patient consultations, a Dual Energy X-Ray Absorptiometry (DXA) (1 region), laboratory tests (blood and urine) and hip and spine $x$ rays. An additional bone profile (bone alkaline phosphatase, osteocalcin, urine N-telopeptide, hidroxipronine, pyridinoline and deoxiypyridinoline) is included for these patients.
Table I

Resource Utilization AND COSTS FOR DIAGNOSIS AND ONE YEAR TREATMENT OF OSTEOPOROSIS at the Instituto Nacional de Rehabilitación FOR 2007 (MeXican PESOS)

\begin{tabular}{|c|c|c|c|}
\hline Resource used & $\begin{array}{l}\text { Utilization } \\
\text { frequency }\end{array}$ & $\begin{array}{l}\text { Unit } \\
\text { cost }\end{array}$ & $\begin{array}{l}\text { Cost per } \\
\text { resource INR }\end{array}$ \\
\hline Outpatient consultation (baseline) & 1.0 & 94.00 & 94.00 \\
\hline Outpatient consultation (follow-up) & 2.9 & 66.00 & 191.40 \\
\hline \multicolumn{4}{|l|}{ Dual Energy X-Ray Absorptiometry } \\
\hline$(D X A)$, I region & 2.2 & 300.00 & 660.00 \\
\hline Blood tests & 1.5 & 114.00 & 171.00 \\
\hline Other laboratory tests* & 1.5 & 319.00 & 478.50 \\
\hline Urine tests & 1.0 & 76.00 & 76.00 \\
\hline Urinary calcium & 0.7 & 71.00 & 49.70 \\
\hline Urinary phosphorus & 0.7 & 108.00 & 75.60 \\
\hline$\overline{X \text {-rays, spine or hip }(2 \text { views })^{\ddagger}}$ & 2.2 & 279.00 & 613.80 \\
\hline Bone profile & 1.0 & 976.00 & 976.00 \\
\hline Drugs $\$$ & N.A. & N.A. & 5665.00 \\
\hline \multicolumn{4}{|c|}{$\begin{array}{l}\text { * Blood tests (glucose, urea and creatine) } \\
\text { ‡ Average cost of x-rays and two projections (hip and spine) } \\
\S \text { Based on data published by Clark, et al. } 2008\end{array}$} \\
\hline
\end{tabular}

The cost per patient diagnosed with OP at the INR for 2007 is estimated at $\$ 2503.00$ Mexican pesos (data not shown). An additional year of treatment with the drugs provided by the INR, (patient interviews and chart review show that $52 \%$ of patients receive alendronate and $37 \%$ receive calcium carbonate, the most frequently prescribed drugs) for a total cost of $\$ 9051.00$ Mexican pesos per patient.

Table II shows the resource utilization diagnosis and annual treatment of OP and hip fracture with the SPSS protocol. The estimated cost to diagnose $\mathrm{OP}$ is almost the same as at the INR (\$2 671.93 Mexican pesos; data not shown) and the two protocols are similar, including: two outpatient consultations, one DXA (one region), laboratory tests and $\mathrm{x}$-rays. The cost of diagnosis plus a year of treatment at the SPSS is estimated at \$8388.58 Mexican pesos, $\$ 662.42$ Mexican pesos greater than the INR cost. The drugs approved by the SPSS for OP treatment are raloxifene, alendronate, hormone replacement therapy and calcitriol. For the SPSS, 90\% of the costs of these drugs are included in the variable cost component. 
Table II

RESOURCE UTILIZATION AND COSTS FOR DIAGNOSIS AND ANNUAL TREATMENT OF OSTEOPOROSIS AT THE SPSS for 2007 (MeXICAN PESOS)

\begin{tabular}{|c|c|c|c|c|c|c|c|}
\hline \multirow[b]{3}{*}{ Action } & \multirow[b]{3}{*}{ Activity } & \multirow{2}{*}{\multicolumn{2}{|c|}{$\begin{array}{c}\text { Fixed cost } \\
\text { Human resources and infrastructure }\end{array}$}} & \multicolumn{3}{|c|}{ Variable cost } & \multirow{3}{*}{$\begin{array}{c}\text { Total cost } \\
\text { (fixed and } \\
\text { variable) }\end{array}$} \\
\hline & & & & & & Laboratory and & \\
\hline & & Outpatient consultation & Hospitalization & Materials & Drugs & image tests & \\
\hline Osteroporosis diagnosis & Outpatient consultation & 269.93 & & & & 2402.00 & 2671.93 \\
\hline Annual treatment for osteoporosis & Outpatient consultation & 596.06 & & & 4397.81 & 722.78 & 5716.65 \\
\hline Total & & 865.99 & & & 4397.81 & 3124.78 & 8388.58 \\
\hline
\end{tabular}

The average cost of surgical management of a hip fracture case at the INR based in the sample prospectively taken from this institution was $\$ 20286.86$ Mexican pesos. This estimate includes: surgical costs (arthroplasty, hemiarthoplasty and fixation), prosthesis; nine days of hospital stay (including one day at the intensive care unit) and the costs of laboratory tests and x-rays before and after surgery and until the patient was discharged. This data was gathered from patient interviews and chart review at the INR. The unit costs are given in table III. For the SPSS, using the same protocol as that described for the INR based in real cases observed between 2005 and 2006, the total cost for surgical management of a hip fracture case was estimated at $\$ 37363.73$ Mexican pesos per patient, almost the double cost charged at the INR (a difference of $\$ 17$ 076.87). In both scenarios the surgery and prosthesis represented the highest cost: \$23 767.03 Mexican pesos at the SPSS and \$10 429.81 at the INR. Information about these costs at the SPSS is shown in table IV. In the SPSS, the distribution between fixed costs (a preoperative consultation, surgery and operating room) and variable costs (consumables, surgical supplies, and prosthesis and fixation devices, drugs, laboratory tests and $\mathrm{X}$-rays) was similar, representing $51 \%$ of the fixed costs and $49 \%$ of the variable cost.

\section{Discussion}

The present study analyzed and compared the costs of two different scenarios: the diagnosis of and annual treatment for osteoporosis, and the cost for acute surgical treatment of hip fracture, in patients 50 years and over from two different protocols in governmental health providers in Mexico. Analysis of costs at the INR was generated with prospective data gathered via patient interviews and medical chart review. Costs for treatment covered by the SPSS was estimated by applying the methods, infrastructure, supplies and costs
Table III

\section{RESOURCE UTILIZATION FOR SURGICAL TREATMENT OF HIP FRACTURE AT THE INSTITUTO NaCIONAL de Rehabilitación for 2007 (Mexican pesos)}

\begin{tabular}{|c|c|c|c|}
\hline Resource & Frequency & Unit cost & Total cost \\
\hline Surgery* & 1 & $57 \mid 1.41$ & 5711.41 \\
\hline Prosthesis ${ }^{\ddagger}$ or fixation procedure $\S$ & 1 & 4718.40 & 4718.40 \\
\hline Standard hospital stay & 8.3 & 354.00 & 2938.20 \\
\hline Intensive care unit & 1 & 4461.00 & 4461.00 \\
\hline Laboratory and image test ${ }^{\#}$ & & & 2457.85 \\
\hline Total & & & 20286.86 \\
\hline \multicolumn{4}{|c|}{$\begin{array}{l}\text { * Includes the surgical procedures arthroplasty, hemiarthroplasty and internal } \\
\text { or external fixation } \\
\neq \text { Includes three types of prosthesis: Thompson, Muller and Spotorno } \\
\text { \& Includes plates (DHS, Richards), nails and screw } \\
\text { \# Based on costs published by Clark et al } 2008(2)\end{array}$} \\
\hline
\end{tabular}

Source: Authorized list of resources and costs from the INR and calculations from reference 4

approved by the SPSS to the treatment data gathered at the INR.

In the case of diagnosis and annual treatment of osteoporosis, the INR and SPSS costs very similar, probably since the unit costs involved were relatively standard, and both organizations use a similar treatment protocol. However, we found important differences in the costs for the acute surgical treatment of hip fracture between the INR and the SPSS: the costs for hip fracture treatment at the SPSS was almost double that of the INR (\$37 363.73 vs. \$20 286.86). The highest proportion of expenditures in both the INR and SPSS were for the costs of prosthesis and hospitalization, though these costs were higher for the SPSS. These differences in 
Table IV

RESOURCE UTILIZATION AND COSTS FOR THE ACUTE MANAGEMENT OF HIP FRACTURE AT THE SPSS for 2007 (MeXican PeSOS)

\begin{tabular}{|c|c|c|c|c|c|c|c|}
\hline \multirow[b]{3}{*}{ Action } & \multirow[b]{3}{*}{ Activity } & \multirow{2}{*}{\multicolumn{2}{|c|}{$\begin{array}{c}\text { Fixed cost } \\
\text { Human resources and infrastructure }\end{array}$}} & \multicolumn{3}{|c|}{ Variable cost } & \multirow{3}{*}{$\begin{array}{l}\text { Total cost } \\
\text { (fixed and } \\
\text { variable) }\end{array}$} \\
\hline & & & & \multirow[b]{2}{*}{ Materials } & \multirow[b]{2}{*}{ Drugs } & \multirow{2}{*}{$\begin{array}{l}\text { Laboratory and } \\
\text { image tests }\end{array}$} & \\
\hline & & Outpatient consultation & Hospitalization & & & & \\
\hline Pre-surgery management & Pre-surgery consultation & 731.02 & & & 0.63 & |38.83 & 870.48 \\
\hline Surgical procedure & Hemiprosthesis * & & 5767.03 & 18000.00 & & & $23,767.03$ \\
\hline Recovery & Hospital stay ** & & 12477.64 & & 109.75 & |38.83 & $12,726.22$ \\
\hline Total & & 731.02 & 18244.67 & 18000.00 & 110.38 & 277.66 & $37,363.73$ \\
\hline
\end{tabular}

*Average of three hours of operating room time ${ }^{* *}$ Average of nine days

Source: CAUSES catalog and calculations from reference 4

costs have two explanations: differences in treatment protocols and differences in the cost of infrastructure.

As was mentioned previously, the estimation of the costs at the INR were based on prospective interviews and chart reviews of hospitalized patients attending this institution, and using the institutions' published cost tabulations. ${ }^{9}$ It is noteworthy that not all hip fracture patients at the INR underwent hip replacement. In fact, external and internal fixation were the most common procedures, used in $85 \%$ of the cases at this institution, and the cost of this type of surgery is lower than that of hip replacement. The estimate per hip fracture patient at the INR therefore was the actual unitary cost, and the global estimate presented for each item represents the average cost per item. In the case of the SPSS, the estimations were done according with their protocol and costs but based on the data obtained with the patients at the INR (e.g. nine days of hospitalization, time of surgery, etc.) but the SPSS protocol assumes that every case of hip fracture will have a hip replacement. Thus, the overall costs for this item carried higher costs at the SPSS. In light of these results, it seems desirable for the SPSS to revise its protocol to include internal or external fixation as potential treatments for hip fracture.

Hospitalization costs also differed between the INR and SPSS. The INR estimate includes an average of $\$ 2938.00$ Mexican pesos for the standard 8.3 day hospital stay, plus one day at the intensive care unit at $\$ 4461.00$ for a total of $\$ 7399.00$ Mexican pesos. The SPSS does not incorporate the cost of the intensive care unit in its protocol, but instead estimates a higher unit cost for a standard day of hospital stay, resulting in a higher total cost at of $\$ 12477.00$ Mexican pesos for a nine day hospitalization at the SPSS. It is important to mention that subsidies for medical attention at the INR are unknown and thus not included, but might raise the actual unit cost for a standard hospital stay at this institution.

Our study had the advantage of access to direct information taken from the patients and charts at the INR and thus reflects a real life example of the resource utilization for hip fracture cases. We are also confident that the unit costs estimated are accurate, since a microcosting of procedures was carried out. ${ }^{4}$ Our application of SPSS protocol and costs to this real life scenario might be a limitation of the study; since we do not know the real SPSS resource utilization per case for hip fracture cases or OP diagnosis and treatment (e.g. the SPSS could have shorter average hospital stays).

In conclusion, we found important differences in costs between treatment of the same OP related problems at the INR and SPSS. The differences found were largely in the cost of surgery, due to the SPSS assumption that all hip fractures will result in hip replacement, as well as different unit costs for standard hospitalization. We thus recommend that revising the SPSS protocol to include the less costly surgical treatments for hip fracture commonly provided at the INR. However, a prospective study to validate the costs at the SPSS is also needed.

\section{References}

I. Johnell O, Kanis JA.An estimate of the worldwide prevalence, mortality and disability associated with hip fracture. Osteoporos Int 2004; I5(II):897-902.

2. Johnell O, Kanis JA, Jonsson B, Oden A, Johansson H, De Laet C. The burden of hospitalised fractures in Sweden. Osteoporos Int 2005; I6(2):222-228. 
3. Clark P, Lavielle P, Franco-Marina F, Ramirez E, Salmeron J, Kanis JA, et al. Incidence rates and life-time risk of hip fractures in Mexicans over 50 years of age: a population-based study. Osteoporos Int 2005; I 6(12):2025-2030. 4. Clark P, Carlos F, Barrera C, Guzman J, Maetzel A, Lavielle P, et al. Direct costs of osteoporosis and hip fracture: an analysis for the Mexican healthcare system. Osteoporos Int 2008;19(3):269-276.

5. Frenk J, Sepulveda J, Gomez-Dantes O, Knaul F. Evidence-based health policy: three generations of reform in Mexico. Lancet 2003;362(9396):|667-|67|.

6. Frenk J, Gonzalez-Pier E, Gomez-Dantes O, Lezana MA, Knaul FM. Comprehensive reform to improve health system performance in Mexico. Lancet 2006;368(9546):I524-I534.
7. Sistema de Protección Social en Salud. Elementos conceptuales,económicos y operativos. In: Económicos UdA, editor. Primera Edición. México: Secretaría de Salud, 2005: I I-38.

8. Zingmond DS, Melton LJ 3rd, Silverman SL. Increasing hip fracture incidence in California Hispanics, 1983 to 2000. Osteoporos Int 2004;15(8):603-610.

9. Instituto Nacional de Rehabilitación. Tabulador de costos de recuperación 2007. México: Secretaría de Salud, 2007.

10. Murray C, Frenk J.World Health Report 2000: a step towards evidence-based health policy. Lancet 200 I;357(9269): 1698-1700.

II. Brundtland GH, Frenk J, Murray CJ.Who assessment of health systems performance. Lancet 2003;36I(9375):2155. 